personal observation. The subjects were all females, and in three of the instances it was taken for the purpose of producing abortion. The symptoms manifested in all may be looked upon as somewhat characteristic. Convulsions of a "tonic" character affecting the whole body ; eyes very glaring and still; jaws set ; hands clenched ; breathing, struggling, choking and strangling; countenance bloated and livid ; pulse from 45 to 60 per minute ; vomiting of a fluid having a strong odour of the oil. As soon as the convulsions ceased, the patients passed into a profound coma. Stertorous breathing, however, continued but for a short time, being soon followed by a peculiar kind of breathing, the chief character of which was " an unsuccessful heaving of the chest in inspiration, and a limpsy dropping together of the chest in expiration." The countenance assumed a bloated aspect ; pulse sank and soon became intermittent; pupils dilated; soft parts about the neck subsided at every inspiration, the whole indicating that venous congestions were taking place in the large venous trunks behind the heart, and that the balance between the circulation and respiration was lost.

Two of the four cases proved fatal. The quantity taken in each was from half an ounce to an ounce. The post-mortem appearances were-the odour of cedar oil given forth on opening the stomach ; the lining membrane of the stomach presented several small red patches, as large as the finger-nail, upon its upper and anterior surface; for some distance around these patches the mucous membrane had lost its usual polished appearance; the duodenum showed marked signs of inflammation. The uterus in each instance was in a healthy gravid state. The usual treatment in cases of poisoning from narcotic irritants was pursued. In one instance marked benefit followed free bleeding.-From Boston Med. and_Surg. Journal, in New York Journal of Medicine, September 1849.

[Savin (Juniperus Sabina), and yew (Taxus Baccata), are generally believed to be the only poisonous species of coniferæ; $J$. Virginiana may now be added to the test. The symptoms in the above cases are very similar to those produced by savin, but manifest more decidedly the narcotic character. The oil of cedar, like that of savin, seems to have no special action on the uterus, abortion, when it does occur, being only a secondary effect of the irritation of the other viscera. It rather appears from the above cases, as well as from what is known of the action of savin, that these drugs, even when they prove fatal to the mother, in a majority of cases fail to produce abortion.

$J$. Virginiana is in common use in America, as a substitute for savin as an issue ointment. Its red wood is well known as that used for making pencils.]

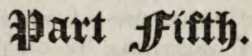

MEDICAL NEWS.

\section{MEDICO-CHIRURGICAL SOCIETY OF EDINBURGH.}

\author{
SESSION XXIX.
}

Meeting I.-November 21, 1849.-James Syme, Esq., in the Chair.

A case of Internal Hernia, remedied by operation, was communicated by the President, and will be found among the Original Communications, page 1 . Dr Simpson made some observations on the diagnosis and removal of intra- 
uterine polypi. Dr S.'s observations will be found in an extended form among our Original Communications, page 3.

The President remarked, that it was curious to observe the amount of irritation and exhaustion produced by some of the smaller excrescences in the uterus. Analogous effects were often observed from slight affections of the rectum. He had, in company with the late Dr Mackintosh, examined a patient with a large tumour protruding from the vagina, and had removed it by transfixion and ligature; some time afterwards he met with another similar tumour in his practice in the Infirmary, and on the occurrence of menstruation from an orifice on its surface, all thoughts of interfering with it were abandoned.

Dr Simpson believed that an inverted uterus had, in some instances, been mistaken for a polypus, and actually removed. In suspicious cases, these lamentable mistakes might be prevented, by measuring the depth of the uterine cavity; if this was much shortened, the probability was, that the uterus was inverted.

\section{CASE OF INTESTINAL CONCRETIONS.}

A communication from $\mathrm{Mr}$ Sharp, of Cullen, giving an account of a case of intestinal concretions, was read by Dr Taylor. The patient, a boy of six years of age, son of a crofter, residing at Stack of Portnockie, parish of Ruthven, Banffshire, was seized with pains in the bowels, on the 5th July, and passed a concretion of irregular shape, and measuring four and a-half inches in circumference. On the following day, his mother had given him a dose of castor oil, and in the afternoon some obstruction in the rectum was experienced, which Mr Sharp found to proceed from the impaction of other two concretions above the sphineter ani. One of these was with some difficulty broken up and extracted piece-meal. The other was drawn out entire by means of the curved handle of an iron table-spoon. It was an irregular mass, six inches in circumference, and two and a-half inches thick. A second dose of castor oil caused the expulsion of a third concretion, of a flattened form, six inches and a-half in circumference, and one inch in thickness. The concretions, when examined with a common lens, were found to consist of a substance like felt, i.e., of fine fibres interlaced in every possible direction, firmly compressed, and in some places resembling silicious matter. The fibres doubtless consisted of mill-dust, the substance derived from the tissue between the cortex and kernal of the oat. The boy, like most in his sphere of life, lived almost entirely upon preparations of oatmeal. He had, for some time before passing the calculi, been in indifferent health, complaining of occasional pains in the side,-declining to take much food,--and, although not so ill as to require confinement to the house, was obviously weaker and less robust than other children of his age. His health had greatly improved since he had passed the concretions.

Three of the concretions were exhibited to the Society.

Dr Bennett made some remarks upon the origin of these calculi. Since Dr Wollaston and $\mathrm{Mr}$ Clift had ascertained that they were composed chiefly of the fibres from the husk of the oat, different observations had rendered it probable, that the interlacement and aggregation of the fibres was due to a true felting process. He alluded particularly to the cases of Dr Turner, of Keith, and to the paper formerly read before this Society by Dr Carmichael. It had been shown, that in the mill, when oats were being ground, the fibres sometimes formed themselves into felt-like masses, and that when oily matter was present, the felting process was effectually prevented. It would, he believed, be found, that the subjects of these concretions lived almost wholly upon oatmeal, and, in particular, that their ordinary food contained no animal matter, or at least no oily or fatty principle.

Mr Goodsir was inclined to think, that the formation of intestinal concretions was, in certain individuals, favoured by the form of the colon. When the gut was large, and furnished, like that of the horse, with complicated sacculi, stasis of its contents might occur, and concretions be formed round a 
nucleus. He mentioned that many of the concretions from the bowels of the lower animals, preserved in the University Anatomical Museum, had, for nuclei, bits of wood, nuts, and, in several cases, from the colon of the horse, a rusty nail. The rusting or oxidation of the iron served to cement the fibres around the nucleus.

A conversation followed regarding the use of chloroform in surgery, and regarding the different modes of its administration practised here and in London. Mr Syme believed, that when carefully used by inhalation from a handkerchief, as originally recommended by Dr-Simpson, the remedy was perfectly safe and manageable, and that inhalers and such-like instruments, were only used where the practice was in its infancy.

Dr Simpson and the President related cases in which operations had been performed without the use of chloroform, and in which symptoms had followed, which, had chloroform been administered, many would have ascribed to its improper use. Mr Syme likewise expressed his belief, that the want of success in the employment of chloroform, which some complained of, was due to the mal-administration of the drug. Nothing could be more annoying to the surgeon than the struggles of an unruly patient, to whom an insufficient dose of chloroform had been given, before commencing an operation. It no doubt required some nerve, on the part of those who used it for the first time, to persist with the inhalation when the patient was violently agitated and convulsed; * yet it was essential to do so, in order to secure the benefits of the remedy, and those convulsive or spasmodic appearances always subsided when the drug was continued. Dr Simpson attached considerable importance to the purity of the drug. When prepared with pyroxylic spirit, instead of alcohol, as was often the case with the specimens used in England, subsequent excitement of the circulation was apt to be produced by the inhalation.

\section{Meeting II.-December 5, 1849.-James Srme, Esq., in the Chair.}

Dr Andrew read the following case of fryouy of the Pelvis during pregnancy, which he had recently treated in the Royal Infirmary.

Martha Rannahan, æt. 30, the wife of a soldier, was admitted into the Royal Infirmary on Tuesday the 4 th of September. She states, that about ten years ago she had a child, and that soon after her husband was sent abroad, and did not return until about eight months since. She now believes herself to be pregnant, and further states, that she quickened about a fortnight since. She was perfectly well until the beginning of August, when she felt pain in the right groin, this was followed by pain in the corresponding thigh and leg, for which blisters were applied by the regimental surgeon with apparent benefit; but on the morning of Wednesday the 28th August, she observed a hard swelling of the right labium.

On admission into the hospital, she has a sallow complexion, much resembling a person labouring under malignant disease, and is of rather a spare habit of body. She does not complain of much pain; the right labium is much swollen (about the size of a lemon), hard, and elastic, the hardness extends up towards the groin. The external aspect of the thigh is œdematous, and the œdema passes up on the posterior part of the limb. The skin is so firmly attached over the hard and elastic nedematous tissue, that it cannot be pinched up. A large tumour can be distinctly felt on the left side of the abdomen, about the size of the uterus at the sixth month; but the abdomen itself is more flat in front than is usual at this period of utero gestation. A very loud sound, similar to the placental bruit, is heard all over this tumour ; but the sounds of a foetal heart can nowhere be distinguished, although carefully listened for.

On examination per vaginam, the os uteri can nowhere be felt; a mass resembling in size and shape the fundus of the uterus, is felt in the left side; but whether this is the uterus displaced, or a tumour, cannot be determined. 
The catamenia have not appeared for four months. The quantity of urine secreted is small and loaded with lithates. Micturition is attended with much difficulty, on account of the swollen state of the labium. The tongue is rather dry, but moist at the edges; the appetite has been bad since she took ill ; the bowels are costive ; she suffers much at present from hæmorrhoids; perspiration is copious.

11th September.-Sometimes an impression as from a living foetus is communicated to the hand when placed on the abdomen, and also when the hand is pressed firmly and suddenly against the tumour on the left side of the abdomen, it is felt to impinge through fluid upon a hard body. There is considerable tenderness above the crest of the ilium on the right side, and a tumour is now perceived in that region. The abdomen is much larger since her admission, and she suffers much from sickness and vomiting.

5th October.-The general health continues much the same as before. Her countenance has assumed a dingy yellow hue, and her features are more pinched in appearance. The tumour on the left side extends from the crest of the ilium to the left hypochondrium, and has a distinet rounded margin. The tumour on right side has also increased somewhat. There is much flatulent distension of the abdomen, which is very tympanitic. On applying one hand above the crest of the left ilium, and the other (cold) over the summit of the tumour, a distinct movement is felt strongly resembling that of a fœtus in utero ; but on auscultating no fotal heart can be heard, although it has struck my clerk (Dr Reid) that on more than one occasion, after the movement in the tumour, he has heard a ticking sound, which might be that of a foetal heart. The mammary areola is very dark and large, the nipple is puffy, and the glandular follicles are enlarged.

14th October.-Has been getting worse ; flatulence continues undiminished; has much sickness, and an almost constant eructation of a watery fluid. As she had passed no urine since the morning of the 12th, the catheter was introduced last night, and about twelve ounces of urine drawn off.

16th October.-Feels easier to-day, and the abdomen is less tense, but she is evidently much lower. The catheter was again introduced yesterday morning, but only about five ounces of urine were drawn off. The nurse states, that during the night the patient passed so much water that it soaked the bed.

Vespere.-Feels easy, but her mind wanders a little, and she is evidently sinking. She died at two A.M. of the 17th. During the time that this patient was in hospital she was seen by several medical practitioners in town, as well as by Dr Robertson and myself, and for some time after her admission great doubts were entertained as to her pregnancy, it being believed, from her general aspect, that the tumour was a large mass of malignant disease ; and this opinion was strengthened by our inability, on examination " per vaginam," to discover any "os uteri," by the situation of the tumour, and by the absence of anything like the sound of a foetal heart. Subsequently however, upon the motions in the tumour on the left side becoming more distinct, and so similar to the movements produced by a live fœtus "in utero," some of the gentlemen who saw her (myself among the number) felt satisfied that she not only was pregnant, but that she had quickened, and that the uterus must have become displaced, and pushed over to the left side, probably by the tumour, which was perceived upon the right side, and which, it was considered, might prove to be malignant, or perhaps a large ovarian cyst or mass of cysts. About a week before her death, on a vaginal examination being made, fluctuation could be felt in the tumour on the right side, just below the pubes; and it was suggested, that some relief might be afforded to the patient by drawing off the fluid by means of a trochar and canula introduced below the pubes through the parietes of the vagina. But the suggestion was abandoned, in consequence of the weak and exhausted state of the patient, and also from

NEW SERIES. - NO. I: JANUARY 1850. 
the uncertainty of the result of perforating a tumour, the nature and contents of which wer e euveloped in so much obscurity.

Sectio Cadaoeris-External Appearance.-Body emaciated, but well formed. The integuments generally were tinged of a yellowish hue. The abdomen was much distended, considerably more so than at the full time of utero-gestation, contrasting remarkably with the general emaciation. Above, the swelling was soft and tympanitic; below, it was of firmer consistence and dull on percussion, more especially on the left side, where a distinctly circumscribed tumour could be felt, of greater induration, and about the size of an ordinary cocoa nut. On the right side, the swelling was prolonged for about two inches into the femoral region. The integuments of the abdomen presented the usual wrinkled aspect of matrons. The mammæ were undeveloped; a well-marked areola existed around each nipple. The right labium was much enlarged, and pitted on pressure. The whole right extremity was larger than its fellow, and from the knee downwards was odematous.

Head not examined. Thoracic Organs healthy.

Abdomen.-On opening it, the stomach and the greater part of the intestines, which were distended with flatus, were found pushed upwards, so as greatly to encroach upon the thoracic cavity, by the enlarged uterus which occupied the left iliac and lumbar regions, and by an irregular lobulated mass which arose from the pelvic cavity. On examination per vaginam, a loop of umbilical cord was found occupying the upper part of the vagina. The os could not be felt. The pelvic contents were now removed en masse. In doing so, the tumour gave way in several places, giving exit to coagula, and to a considerable quantity of a dark, reddish-brown, grumous fluid. It was found to extend up as high as the lower margin of the kidney ; and in front it was adherent to the abdominal parietes for about three inches above the pubes, especially on the left side. It occupied the entire cavity of the pelvis, dislodging the bladder upwards and forwards. For the most part it was situated beneath the peritoneum ; but on the left side, and behind the uterus, its covering seemed to consist only of cellular tissue. On section, it presented large masses of dark coagula enclosed in imperfect cysts (the walls of which in several places had a white fibrous appearance), together with dark grumous fluid. In all directions it broke down easily under the finger.

The uterus was displaced laterally, its anterior surface looking towards the left iliac fossa. In front and behind it was free, but, laterally, it was partly adherent to the morbid mass. It contained a male fœetus of about the sixth month, of which the cuticle was commencing to separate. The presentation was footling. The placenta was situated on the posterior wall, and admitted of easy separation. The ovaries and Fallopian tubes were intact. The right ovary, on section, presented a corpus luteum, with a stellar cicatrix in its interior : a minute depression marked its presence externally. A small serous cyst was found attached to the Fallopian tube of the same side.

The entire surface from which the tumour had been removed was covered with debris, which admitted of easy removal with the finger. The peritoneum covering the right iliac fossa separated with ease, the bone below presenting a rough and worm-eaten appearance. The surfaces of the sacrum and ilium forming the right sacro-iliac synchondrosis were found separated to a considerable extent, at one point admitting the distal phalanx of the index finger. At the upper part of the articulation, ligamentous bands still kept the bones in contact, but below, not a vestige of them was to be seen. The bones, however, admitted but of slight motion upon one another. The iliac artery and vein having been removed along with the tumour, it could hot be made out satisfactorily whether a rupture of these vessels had taken place or not. The prolongation of the tumour into the groin was situated above the femoral vessels. It consisted of loose coagula. The femoral artery and vein were perfectly pervious, and appeared normal.

Under the microscope the fluid exhibited blood-globules and fibro-plastic 
cells, while the coagula and the walls of the so-called cysts, presented delicate fibres in every stage of development.

The circumstance of the umbilical cord being found in the vagina at the "post-mortem" examination indicates that the membranes had ruptured, and this probably occurred during the night of the 15th, as the nurse reported at the visit hour on the 16th, that during the night the patient's bed had become wet, which is sufficiently accounted for by the escape of the liquor amnii. During the "post-mortem" examination the husband of the deceased was present, and when the diastasis was discovered, he was asked if he was aware whether his late wife had met with any accident or violence previous to her admission into hospital ? In reply, he stated, that about the 20th of July last, as his wife was entering one of the barrack rooms with her arms full of clothes, the door was accidentally slammed to with great violence, and struck her upon the right hip. The blow was so violent, that the woman was knocked down, and remained for a considerable time in a state of insensibility. It would have been interesting could we have traced out the source of the hemorrhage; but this was impracticable, owing to the destruction of the adjacent parts by the removal of such a mass of foreign matter. The history of the case, however, seems to indicate, that the tumour was formed by hemorrhage from small vessels, as had it proceeded from the rupture of a large arterial or venous trunk, it is not unreasonable to suppose that the hemorrhage would have proved fatal by syncope at an early period; whereas the tumour increased but slowly, and the patient sank exhausted after many weeks of suffering.

Dr Simpson, who had seen the patient in the Infirmary, had had some difficulty in forming a diagnosis. There was certainly evidence of tumour, but the question to be solved was its precise nature. He had observed that the cutaneous veins on the right side of the abdomen were enlarged, to an extent unusual in cases of ovarian disease. He had believed the disease to be a malignant tumour beneath the peritoneum, and most gentlemen who saw the patient had formed a similar opinion.

ANEURISM OF THE SUPERIOR MESENTERIC ARTERY OPENING INTO THE DUODENUM, TWENTY-TWO MONTHS BEFORE DEATH.

Dr W. T. Gairdner read the following communication on a case of aneurism of the superior mesenteric artery.

M. C., æt. 26, servant, was admitted into the Royal Infirmary, under Dr Douglas, January 4, 1848. During the twenty-four hours previous to her admission, she had brought up, by vomiting, large quantities of blood, on six different occasions, The vomited matter consisted of clotted blood, with a good deal of fluid, and might have amounted in all, according to her statement, to half a gallon. The vomiting had ceased on admission.

She dated her complaints from the summer of 1847 , when she had jaundice, accompanied by some sickness and vomiting, and by pain across the chest and back. She was not confined to bed; but became afterwards sensible of diminished strength. About six weeks before admission, she had suffered from the prevailing influenza, during the progress of which she frequently had vomiting of a sour acrid fluid, sometimes to the extent of half a gallon at a time. The vomiting occurred usually in the evening, after dinner; never after breakfast. She also suffered from constant pains, extending from the back to the pit of the stomach, and from a feeling of tightness in the chest, especially when she had on stays, or heavy clothing. She had little or no cough at any period of the complaint.

She was admitted in a state bordering on syncope; the surface was very pale; the circulation hurried. The slightest exertion seemed to cause fainting, accompanied by the peculiar pain in the abdomen from which she had been suffering. When seen next day, she had vomited about half a pint of blood since admission; the blood was coagulated. She fainted at the time of the vomiting. She was free from sickness; but there was tenderness in the hepatic 
region, with slight extension of the dull percussion. The breath fœetid; the tongue with a slight grey fur ; circulation hurried. (Digitalis and ipecacuan.) She continued in the same state for twenty-four hours more, unable to rise without a feeling of vertigo. The pulse, on the $6 \mathrm{th}$, was 103, soft and quick. From this time to the evening of the 7 th she improved steadily. On the evening of the 7 th (third day from admission), she had repeated vomitings of blood, preceded by headache and sickness. The quantity vomited was not exactly known. She was more anemic than before, and the epigastric tenderness was more considerable, but chiefly on the right side. A slight pulsation of the abdominal aorta is noted in the report, and an impairment of percussion on the right side of the epigastrium. From this period (four days after admission) she had no return of any bad symptom ; and, by rest and careful regimen, she became rapidly convalescent. She remained in the house till February 7 th (one month), when she was dismissed cured. After this, I saw her several times in the surgical house. She had been admitted on account of a weak ulcer on the back of the left leg, which usually bled at the menstrual period, and was slow to heal. She was still pallid and languid, and suffered from dyspeptic symptoms, with amenorrhoea, but had no return of vomiting. She was sent out with her ulcer nearly healed. I heard nothing more of her till I learned that she had fallen down suddenly, in the street, and had been found by the officers of police in a fainting state. She died before she could be removed to the hospital, whither the body was immediately brought. This was on November 28, 1849 (twenty-two months from, first occurrence of hæmatemesis). ${ }^{1}$

The dissection was performed next day (November 29th).

The body was pale, but not at all emaciated

On making the first incisions through the parietes, the cause of death was at once revealed in a large quantity of clotted blood, which was found in the peritoneal cavity. The coagulum, on being removed, weighed $2 \frac{1}{2} \mathrm{lbs}$. ; so that I think considerably above 3 lbs. of blood must have been extravasated.

The thoracic organs were healthy; but the left side of the heart was small and firmly contracted; and the thoracic aorta was also small.

The great abdominal glands were all healthy, but very anemic. The liver and spleen were bound up to the diaphragm by rather loose but dense adhesions ; thus fully accounting for the tenderness during life in the left hypochondrium. In the angle between the lower part of the duodenum and the head of the pancreas, there was found a ragged lacerated opening through the serous membrane. The edges of this opening were not all thickened. The pancreas was normal in size and structure, but appeared to be displaced forwards and somewhat stretched over a small tumour, situate behind it, on the front of the vertebræ and great vessels. To ascertain the nature of this tumour, the biliary ducts (which passed very close to it at its right side, but had apparently no connection with it) were cut across, close to the liver. The aorta and vena cava were then divided below the diaphragm, and a considerable portion of these vessels, with the stomach, duodenum, and pancreas, were removed en masse.

Being strongly prepossessed with the idea that there had been some ulceration of the stomach, giving rise to the profuse vomitings both of blood and alimentary matters to which she had been subject, I slit open this organ, and examined every part of the mucous membrane with great care, but without discovering anything abnormal. I then continued the incision into the duodenum, and carefully looked at the mucous membrane, at first with a similarly negative result. The coats of the intestine, however, were at one point very

1 Since the above was written, I have learned that she was, for a few days, in another ward in the house, in October last, affected with deep jaundice; and also that she had led an irregular life, having, at a previous period, suffered under syphilitic
ulceration of the ear. 
thin, and slightly ecchymosed ; this part was found to be in the immediate neighbourhood of the before mentioned opening through the peritoneum, which had given rise to the fatal bleeding. On more minutely inspecting the mucous membrane, I found a very small ecchymosed spot, slightly elevated, and perforated in the centre by a minute opening, from which a very little bloody fluid could be squeezed by gentle pressure. A moderately fine probe could be passed a line or two into this opening, but was there arrested ; and no attempt was made with a finer instrument. This cicatrix was situate about two inches lower in the gut than the opening of the biliary vessels, and very close to the site of the external peritoneal opening.

On slitting up the aorta from behind, it was found to be, like the part of the vessel examined in the thorax, nearly, if not absolutely, free from disease or deposit. The opening of the superior mesenteric artery, however, was a little irregular in form; and, on passing a probe through it, a considerable dilatation was discovered in the line of the vessel, occupying the whole first portion of its trunk, and corresponding in situation with the tumour above described. A little further manipulation enabled me to push the probe downwards, through the ragged opening in the peritoneum.

The sac was now divided by an incision to the left of the mesial line, passing through the peritoneal opening. It was seen to be composed of a thick and strong fibrous cyst, slightly oval in form, and not larger than a hen's egg, somewhat flattened antero-posteriorly, and with its long diameter in the axis of the artery: This cyst had evidently ruptured at its lowest point, and the blood had made its way through the cellular tissue between the coats of the duodenum, breaking up the muscular coat into two layers, and finally perforating the serous coat by a ragged opening. The sac contained a number of irregular and half-decolorised coagula.

The condition of the coats of the mesenteric artery itself, at the point of origin of the aneurism, was not investigated, the parts being sent to the University for further dissection and for preservation. The continuation of the artery was also not examined. The coeliac axis was healthy, but perhaps rather larger than usual; the other branches of the abdominal aorta appeared all normal. The splenic vein, which lay close upon the side of the tumour, but, as far as could be observed, without any communication with it, was somewhat dilated, and contained a very firm coagulum of decolorised fibrine.

It was now evident that the disease was an aneurism of the superior mesenteric artery, which had opened primarily into the duodenum, giving rise to very copious vomitings of blood, twenty-two months before death; that this opening had become entirely or nearly closed, and that death finally took place from a second opening, not far from the first, into the peritoneal cavity.

In this view of the case, the whole of the collateral symptoms become of easy explanation. The occasional jaundice was evidently owing to the pressure exerted by the tumour, when at its extreme point of distension, on the biliary duct ; while the sickness and vomiting of sour matter, after a full meal, so evidently relieved after each hemorrhage, may have been owing to a similar pressure on the duct of the pancreas interfering with the duodenal digestion. The nearly constant pain produced by exertion, and the feeling of tightness and oppression caused by the use of stays, or any other article of dress which compressed the abdominal organs, may be obviously explained by the injurious pressure effected in this way on the tumour, and on the great blood-vessels which lay beneath it. The tenderness of the epigastrium and right hypochondrium were probably not directly connected with the deep-seated lesion, and rather seem to have resulted from the inflammation in the serous lining of the liver, which produced the adhesions found after death. The slightly increased size of the liver, as shown by the extended dull percussion in the hypochondrium, probably was caused by the obstruction of the vessels and ducts of the organ. The lassitude, diminished strength, anemia, and amenorrhœea, were evidently owing to the great and repeated loss of blood; and obstinate continuance of 
the anemic state during the long interval between the attacks of hemorrhage, may have been caused by the imperfection of the digestive process. The existence of pulsation in the epigastrium needs no explanation.

At the same time it is to be observed, that the whole of the phenomena under observation at the time of the first attacks of hæmatemesis, were such as to lead directly to the supposition of a chronic ulcer of the stomach. The comparative frequency of this disease in young females, the whole progress of the case, and, finally, the apparent cure, by simple remedies and careful regimen, were calculated to confirm this diagnosis ; and even on now reviewing the recorded facts of the case, I do not think that any of the prominent symptoms can be considered as opposed in any way to this opinion. The following symptoms, at least, appear sufficiently equivocal in character :-

1st. The hæmatemesis. Profuse hemorrhage, as a consequence of chronic ulcer of the stomach, involving the coronary artery as one of its branches, has been repeatedly observed, as in the cases of $\mathrm{Dr}^{\text {Craigie }^{1}}$ and others.

$2 \mathrm{~d}$. Sickness and vomiting after eating, with dyspeptic symptoms of various kinds, are nearly constant phenomena in chronic gastric ulceration.

3d. Dull pain, increased by exertion or repletion, with tightness and oppression at the epigastrium, are equally characteristic symptoms of the disease in question.

4th. Anæmia was the obvious consequence of the loss of blood; the tendency to syncope, the lassitude, and the diminished strength, were equally so.

5 th. Lastly, in the category of the equivocal symptoms, I must also place the slight epigastric pulsation which existed in this case, unaccompanied by any appreciable tumour, from which its true nature might have been inferred. The extremely frequent occurrence of such a pulsation, in connection with dyspepsia, would of itself have been, in the present instance, a sufficient reason for the absence of any suspicion; but the probabilities in favour of its being what is so well known as "nervous pulsation" of the aorta, were greatly increased, when it is considered that the whole arterial system presented the vibratile pulsation, which so of ten follows profuse hemorrhage.

There remains, then, of the actually observed symptoms, only the jaundice. Now jaundice is, to say the least, far from being a characteristic symptom of aneurism of the abdominal vessels, while, in the present instance, the tenderness in the hepatic region and extension of the dull percussion, seemed to point to an accidental affection of the liver itself as its source.

But is there any symptom, or collection of symptoms, which, in another case similar to the present, might lead to the establishment of an unequivocal diagnosis? On reviewing the whole case, it appears to me that the following points merit consideration :-

1st. The stethoscope might have revealed a bruit, single or double. If the sound had been double, the nature of the case would nave been no longer doubtful; but if a single sound only had been heard, as is commonly the case, it would have been open to question, whether it was produced by an aneurism, or by some other deep-seated tumour pressing on the aorta. Nay, in the pulsation which is independent of organic disease, I have occasionally heard a distinct bruit, on applying moderate pressure with the stethoscope over the vessel.

But, farther, there might have been no aneurismal bruit. This peculiar phenomenon depends, in great part, upon the dilatation of the aneurismal sac at each impulse of the heart ; and there is reason to think that an aneurism, so closely bound down as the present, would be accompanied by but little murmur. In fact, in a case related by Dr Hope, where an aneurism, considerably larger than this one, sprang from the right side of the aorta, half-an-inch below the coliac artery, there was no aneurismal bruit, only a superficial whiff, which proceeded from the superior mesenteric artery, stretched over the front 
of the tumour. This is the only case I can find bearing on the question. In the present instance, I do not remember that a stethoscopic examination was made; but if so, the results must have been negative.

$2 d$. The pain and vomiting, after taking food, might have presented a peculiar character, had inquiry been made. If these symptoms proceeded, as is most probable, from impediment to the duodenal digestion, they would occur an hour or two after food had been taken; whereas, in the case of ulceration of the stomach itself, the pain would rapidly follow the meal.

$3 \mathrm{~d}$. The jaundice, if its intermission and recurrence had been the subject of frequent and continued observation, might probably have been attributed to pressure or obstruction of the ducts, rather than to a disorder of the liver itself ; and this circumstance would probably have led to a closer examination of other symptoms and signs.

The most practical conclusions to be drawn from this remarkable, and so far as I know, unique case, appear to be the following: That the combination of jaundice, with symptoms indicating imperfect pancreatic digestion (cardialgia, pain and vomiting some time after taking food), should, in all cases, lead to the strong suspicion of a tumour pressing on the ducts of the liver and pancreas, near their duodenal termination;- that the co-existence of these symptoms with fixed pain or oppression in the epigastrium, pulsation in the same region, and hæmatemesis, would very probably indicate aneurismal tumour, even in the absence of more unequivocal signs; and that this diagnosis would not be invalidated by the arrest of the hæmatemesis (even after repeated recurrence), or by the apparent cure of the affection; while, on the other hand, it would be rather confirmed if the remission of the pain and other rational symptoms immediately after each bleeding, were as marked as in the present instance.

I think, however, it may also be said, with truth, that none of these symptoms or phenomena, would suffice absolutely to point out the true state of the case, unless unequivocal signs of an aneurism were presented on stethoscopic examination.

\section{Appendix.}

Aneurism of the superior mesenteric artery is exceedingly rare in man. Since the above case was read to the Society, however, my attention has been called to four cases of it.

In the "Lancet" for 1835 an instance of this affection is described, in a patient who died of scarlatina, under Dr Elliotson. It was as large as a human heart, and had formed during life a pulsating tumour above the umbilicus. It was attended by severe pain in the lumbar, epigastric, and umbilical regions, and also with occasional nausea and vomiting after taking food. The sac remained entire up to the period of death.

Two interesting cases of superior mesenteric aneurism are related by Dr J. A. Wilson, in the "Medico-Chirurgical Transactions," vol. xxiv., p. 221 ; and it is very remarkable that one of these cases ended by jaundice, while the other was accompanied by vomiting of large quantities of blood. The blood, however, in this latter case, does not appear to have come from the aneurism, but from the lung, the patient being affected with profuse hæmoptysis, from phthisis. No symptom of digestive derangement is recorded in this case, except obstinate constipation. The aneurism was large, easily felt in the epigastrium, and attended with pain.

In the other case the jaundice was very marked while the patient was under observation. There was also pain between the shoulders, and in the line of the dorsal vertebre, as well as occasionally in the epigastrium and hypochondrium ; exhaustion, loss of muscular power, depression of mind, and loss of appetite, but no tumour or pulsation, although frequent examination was made. Neither vomiting nor sickness are mentioned. The aneurism was also large, and in the trunk of the artery, about an inch from its origin ; it was closely in contact with the ductus communis, which, however, was pervious.

In the "Medical Gazette" for 1842 (Feb. 25), Mr James Douglas relates a 
case of thoracic aneurism, complicated with small aneurisms of the coeliac and mesenteric arteries. These latter presented no symptom during life, except vomiting, which occurred when exertion was made after taking food.

Aneurisms of the cœliac axis and its branches are somewhat more common than those of the superior mesenteric. In one case alluded to by $\mathrm{Mr}$ South (Translation of Otto's Pathological Anatomy, vol. i. p. 320), in the Museum of St Thomas's Hospital, the aneurism " by its motions against the stomach, produced vomiting whenever food was taken, and the patient died of consequent starvation." The museum of the College of Surgeons of Edinburgh contains a preparation (Catalogue, No. 1152) of aneurism of the hepatic artery, in which the superior mesenteric is also considerably thickened and dilated; but no particulars of the case are given. In the same museum (No. 1146) is an aneurism of the abdominal aorta involving the cœliac axis; the superior mesenteric artery issues from the lower border of the sac, but is very slightly involved in the disease. In this case the sac burst into the cellular tissue, and the extravasated blood became encysted, forming a secondary sac, the rupture of which caused death. The existence of the aneurism was: not suspected during life, and the patient was treated for hepatitis. We may, therefore, presume, that jaundice was probably present in this case.

The case of aneurism of the hepatic artery, by Dr Stokes, adverted to by $\mathbf{M r}$ Goodsir (p. 89), is in the Dublin Journal, vol. v., p. 401. The tumour was bound down by the capsule of Glisson, and therefore in close connection with the ducts, which were singularly dilated throughout the liver, forming projections on its peritoneal surface. In this remarkable case, the first symptom was copious hæmatemesis ; and, from this fact, together with the singular dilatation of the biliary ducts, I connot help suspecting, that the aneurism had opened into them,- a circumstance which might easily have been overlooked. In a letter to Dr Stokes, cited in this paper, Dr Harrison incidentally notices having seen an aneurism of the mesenteric artery. He also observes, that haematemesis frequently accompanies abdominal aneurism ; and that in one case, where examination after death took place, the aneurismal sac had no communication with the stomach.

The museum of the College of Surgeons of Ireland contains two instances of aneurism of the abdominal aorta bursting into the duodenum (Dr Houston's Catalogue, B. c. 268, 269). The history of the cases is not given, nor are the anatomical relations of the aneurisms stated.

In the museum of St Bartholomew's Hospital (thirteenth series, 68), there is an aneurism of the abdominal aorta, extending from the superior mesenteric artery to the bifurcation, which ruptured into the duodenum four days before the death of the patient. I am indebted to $\mathrm{Mr}$ Paget for some particulars of this interesting case, copied from the books of the hospital. The man had been sensible for two years of a pulsation just below the scrobiculus cordis, which he perceived for the first time after a fall from a scaffold. In the two days before death, he had repeated discharges of blood per anum, preceded by severe pain, which was relieved by the discharge. The opening into the duodenum was found, after death, to be regular and smooth-edged.

In this, and most of the other cases of abdominal tumour I have referred to, the coats of the vessels were diseased. In the case I have narrated, however, the nearly healthy state of the aorta seems to render it probable that the aneurism was the result in some way or other of violence applied to the artery. The sac was very strong and dense, but its relation to the coats of the vessel could not be distinctly made out without destroying the preparation.

The President considered Dr Gairdner's communication highly interesting, as confirmatory of the observations which have now been frequently made, that the bursting of an aneurism of a large vessel was not always fatal. The hemorrhage might cease when the aperture became plugged up, and the patient, restored to apparent health, might, after the lapse of months, die of some disease unconnected with his original complaint. In illustration, he read a 


\section{very interesting communication from $\mathrm{Mr}$ Ramsay, surgeon at Broughty Ferry :- \\ " On the subject of the rupture, and subsequent temporary cure of aneurism,} allow me to add a very interesting case which occurred in Cupar Fife, in the summer of 1834, in the person of Alexander Grant, æt. 50 to 55, short and muscular, of rather intemperate habits, a porter to an iron merchant. I saw him frequently during the summer above mentioned; the tumour was situated on the upper and left side of the chest. During my visit to Cupar, in the Christmas recess, I called for Grant and found him confined to bed, very weak from the loss of a large quantity of blood, that had taken place a few days previously, and from a rupture opposite the cartilage of the third rib, whence a stream of blood, somewhat larger than a quill, immediately issued. Grant, nothing alarmed, got hold of a bowl, held it at arm's-length to receive the red arch which he supposed was the contents of a "bloody boil," pressing the tumour with his chin to effect a more speedy clearance ; after about a quart of blood had gushed out, Grant fainted, and the bleeding stopped and dried over the opening; the vascular action being so much reduced by this extraordinary depletion, allowed the integuments in some measure to collapse and cicatrise under the dried film of blood. As I expected to be absent from Cupar during the remainder of the winter session, and greater part of summer, I requested my master, Mr Adam Wisemann, to remove the parts and preserve them. In November 1835, I was informed that Grant had lived four months without any new rupture; he did not die from the aneurism, but from typhus fever. I had the satisfaction of examining the parts, which had been carefully dissected. The aneurism involved the arch and innominata; absorption of the second, third, and fourth ribs, parts of the clavicle and sternum; the cicatrix well defined. I believe the preparation is still in Edinburgh."

Dr Gairdner had, many years before, presented to the Society a case of aneurism which had burst into the left bronchus, and had recorded it in the forty-third volume of the " Edinburgh Medical and Surgical Journal.". After expectorating a considerable quantity of blood, the patient continued in tolerable health for ten days, when he suddenly expired in the act of dictating to a clerk, a profuse discharge of blood having taken place from the mouth. On dissection, two communications were traced between an aortic aneurism and the left bronchus; the upper one was plugged up by coagulum, the lower one had been more recently formed, and given vent to the fatal hemorrhage.

Dr Bennett remarked, that when an aneurism opened upon a mucous surface, the aperture was usually small; it was not unusual to find several small perforations which might easily become obstructed for a time by coagula, as in the cases just related to the Society. When, however, aneurism opened into a serous sac, the aperture was for the most part so large as to cause sudden death, by extensive hemorrhage.

Dr Douglas explained the grounds upon which he had treated the patient, twenty-two months before her death, when she first vomited blood, rather as the subject of chronic ulcer of the stomach than of aneurism. The patient was but twenty-six years of age, a period of life at which the chronic ulcer is often met with in females, and at which aneurism is comparatively rare. Hæmatemesis is likewise not uncommon at this age, and the abdominal pulsation is not a trust-worthy sign of aneurism in such patients. Possibly a more correct diagnosis might have been arrived at, had he considered that the patient's general health was not so much disturbed as is usual in cases of chronic ulcer of the stomach. In particular, the digestion was not seriously depraved, nor was there complaint of constipation. Even had the existence of aneurism at this early period been suspected, it would, in all probability, have eluded detection on physical examination.

Mr Goodsir called Dr Gairdner's attention to a case recorded by $\mathrm{Dr}$ Stokes, of Dublin, in which an aneurism of the hepatic artery caused jaun-

NEW SERIES.-NO. I. JANUARY 1850. 
dice, by compressing the hepatic ducts. He also alluded to some curious cases of the same description, referred to by Otto, in his Pathological Anatomy, by Dr Donald Munro, in the "Medical Essays," and by Sir John Pringle. In some of the lower animals, aneurism of the superior mesenteric artery was not unfrequent. Thus, it had been often observed in the horse, and still more frequently in the ass. Rudolphi had pointed out that entozoa (Srongylus Armatus) were often met with in great numbers in the aneurisms of the superior mesenteric of the horse and ass. These worms lay within the aneurismal sac, their tails being entangled in the fibrous clots, while their heads were free and exposed to the current of blood. But they were found in other situations within the abdomen ; thus Morgagni had described them as occurring in tubercular masses outside the vessels. About three hundred years ago, Tyson, an old English anatomist, on dissecting a peccari, found the abdominal aorta to be uniformly dilated; and Daubenton having long afterwards made a similar observation, the aneurismal condition of the aorta was for a time believed to be the normal structure of the peccari. Cuvier had pointed out the fallacy of this idea, by showing, that, in the young animal, the aorta was not dilated. Rudolphi had ingeniously speculated upon the possible connection between the aneurisms affecting the human subject, and the existence of entozoa in the blood ; some old writers had gone a step farther, and believed that the erosion of the aneurismal sac was effected by the ravages of an animal parasite. The strongyli had been found in different parts of the circulating system, and their presence was not necessarily associated with the existence of aneurism. In answer to a question from the President, Mr Goodsir stated, that a species of strongylus had been observed in the heart of the porpoise, and in the bronchial tubes of the same animal. He repeated that the " habitat" of these worms was not always within the arteries.

Professor Dick, of the Veterinary College, had, in the course of his dissections of the lower animals, been long familar with aneurisms of the mesenteric artery, and with the presence of worms in their interior. The worms were found both in the horse and the ass, more frequently, however, in the latter animal. They were found of all sizes, and in the most different textures. Thus he had seen them on the mucous surfaces, enclosed in a small nucleus or cyst, in the arteries, in the brain, even in the spermatic cord. He exhibited to the Society specimens of the strongyli. Aneurisms were not very often met with in the horse ; he, however, produced examples of the disease, both from the aorta and from the internal carotid. In the latter instance, the animal had died from hemorrhage consequent upon rupture of the sac into the nostril. So common, however, were the dilatations of the mesenteric artery in the ass, that Mr Dick had ceased to look for them, having satisfied himself that they existed in almost every ass that was examined. Their presence gave no inconvenience, and did not cause the death of the animal ; neither could they be detected during life. Mr Dick showed a specimen of mesenteric aneurism taken that day from the body of an ass in his dissecting room, and other examples of the worms alluded to, which had been obtained from the bronchia of the calf.

Dr Simpson made some observations upon the frequency of hæmatemesis in young women from obstructed catamenia, and totally unconnected with serious organic disease.

Dr Bennett mentioned that on opening the body of a young female, who died under Dr Craigie's care, in the Royal Infirmary, he found the stomach quite full of blood ; but not a trace of aneurism or other organic disease could be
detected.

\section{SUMMER QUARTERS IN THE PUNJAUB.}

Our readers will peruse with interest the following account of the heat and consequent sickness experienced by European troops quartered about Peshawur during the past summer. 
The letter from which these extracts are taken, was written by a medical gentleman in her Majesty's service, and is dated Peshawur, 26th September 1849.

"And first, thank God, we have at last got to the end of the hot season, for four months of such misery I never experienced anything like, nor will I ever again if I can help it. We remained encamped on the plain at Jumrood till the 6th May. It had before then been getting hot, but thunder-storms every few days cooled the air again. It was curious to observe how electricity accumulated there in certain objects, such as the canvass of the tent, after two or three hot dry days. Drawing the hand, or sweeping a towel inside along the walls or fly of the tent, or along one's bedding, and even the iron frame work, produced a broad streak of sparks, almost like a small flash. One night, late, a thunderstorm came on overhead, but instead of the dense clouds one is accustomed to see lightning from, there was only a thick, partly transparent, haze, through which the lightning darted; and it seemed, and was almost felt, as if all about one. It was not comfortable. I think it was that night a severe accident occurred from it in our regimental bazaar close to us. I wonder if it was connected with this state of electricity, that almost every man throughout the camp complained more or less of nausea, sometimes proceeding to extremities. In some the "extremity" came on suddenly, without nausea, or the slightest warning, and at awkward times. The whole force marched from Jumrood on the 6th May, and encamped by regiments in various places round the town of Peshawur, until the different buildings should be ready for them against the hot weather. The very next day the hot weather fairly set in with a scorching hot wind from the hills to the north-west. Day after day we were treated for many hours to these furnace blasts, the interval being never cool. Sometimes they came on at sunrise, and blew the whole day, with clouds of dust; but any hour in the twenty-four was quite the same to them. About eight or nine in the evening was a frequent time, lasting all night, or a great part of it. The thermometer would even then at once rise to $100^{\circ}$ and upwards. Everything one touched seemed hot. One's garments, on putting them on, felt as if they had been aired at a fire to singeing. You may imagine what a comfortable night's rest we had. After a time some of us got tatties, made of a thorny plant, which grows in abundance around, and by keeping them constantly wet, and letting the wind blow through into the tent, a pleasant temperature was obtained-a hot wind was then wished for rather, as it was the only means by which one could be cooled. Others dug holes in the ground under the tents, and got into them during the heat of the day. $* * * \quad * \quad$ Some were glad to get places exactly resembling small prison cells, only they would scarcely be considered fit even for criminals in England now-a-days. On first coming, I frequently took refuge in one of them during the heat of the day. One gentleman, Major D., got possession of a deep dry well, dug a huge subterranean staircase leading to the bottom of it, and there remained from six A.M. till six P.M. ; but whether he succeeded in all that time in finding what is said to lie in such places, I know not; but this I know, I was several times glad to join him in the search, as it was the coolest place of the whole till my own was ready. I did not like the house, but chose a clump of very large mulberry trees in the adjoining orchard. The trees are quite equal to large elms, and give an excellent shade. In the centre of the clump I had my tent pitched, and a large thatched pent-roof built over it. Inside the walls of the tent the ground is dug out to the depth of six feet, giving me an apartment of about twelve feet square; the walls are matted round; and here, with the aid of a punkha overhead, constantly pulled, I have got through the hot weather as well as most. The thermometer never rose above $96^{\circ}$ in it. I get in and out by a wooden ladder. It al ways puts me in mind of a bear's den in the zoological gardens, and many a good growl I have had in it. I have another tent pitched in the garden for sleeping in.

The ground in the orchard is frequently irrigated from the numerous streams that are led through for the purpose; from the constant moisture, when the sun gets low, it soon becomes cool in the orchard, at least comparatively so; 
then the change in the evening into the dry bare ground, where the buildings and tents stand, is quite sickening from the heat. It always gave me the same sensation as sitting at dinner with my back to a large fire, a predicament in which I have been more than once. The thermometer at a late hour in the evening ranged from $95^{\circ}$ to $100^{\circ}$. Imagine, then, sitting down to dinner at such a temperature ! It continued hot all night, and there was nothing for it but to sleep in the open air. As to exercise, such a thing could not be even thought of. Fortunately, in the garden is a well of the depth of some seventy-five feet, and the water in it is very good, and always at a temperature of $55^{\circ}$-this was one great luxury ; besides its own refreshing drink, it cooled all wines, \&c., and throwing half-a-dozen chatties of it over the body was the only agreeable solace of the twenty-four hours. In addition to the heat, is another terrible torment, the sand-flies, they are so small and colourless as to be with difficulty seen ; they are furnished with a proboscis like a gnat, with which they go poking away into the skin, clothes or no clothes, ten times oftener and more rapidly than a musquito; they are so numerous, too, that no musquito curtain can keep them out.

"In the beginning of June, fever began to attack a number both of men and officers, from 20 to even 60 a-day being admitted to hospital, and at one time we had upwards of 200 men on their backs with it, besides a great number hors de combat. Fortunately in very few was it of longer duration than two days, but it was smart, and left the patient reduced and weak to an extraordinary degree. In that month we had upwards of 600 cases of fever in hospital, and lost five, three of them from congestive apoplexy, as the Bengal people call it, supervening. With, I think, only one exception, every officer in the regiment had this fever, some twice, and even thrice. At its height, first one assistant-surgeon and then the other caught it, so you may suppose the labour that devolved on me for a few days, in such a temperature, was no trifle. The thermometer used then to rise in the day time to $103^{\circ}$ in the hospital, and to $105^{\circ}$ in the barrack-rooms, several of which we had to convert into wards. At sun-rise from $86^{\circ}$ to $90^{\circ}$ in the wards ; the latter temperature was in August.

"The fever was at first thought to be owing to the particular locality, but it subsided in this locality towards the beginning of July, and then attacked the European soldiers on the other side of the town, on a kind of locality quite different - open and dry. Almost every European in the place had it, excepting one regiment located in the town. I held out so long that I thought I was to escape; however my turn came. It lasted the usual two days, and then left me wasted and helpless like the rest. Instead of the usual return of desire for sustenance on the subsidence of fever, there was for ten days perfect indifference, or rather dislike, to everything, even to cold water or drink of any kind ; and it was many days after that, before a proper relish for food returned. Almost all were the same; and a most melancholy set of scare-crows-ghosts of their former selves-were to be seen crawling about, instead of the fine body of men, full of health and spirits, that had marched into Peshawur three months before. July was better; two or three thunder-storms with rain revived us all wonderfully, and our sick list fell to 70. Up again in August, the temperature higher than ever, and becoming daily more oppressive from the air getting loaded with moisture. The 13th was a terrible day. In the afternoon four men were attacked, all within a few minutes, with congestive apoplexy, and several more were threatened with it. All were in hospital with slight attacks of fever. Three died in a few hours, making seven deaths from the same cause since the first of the month, and twelve during the hot weather. The 14th day commenced still worse, the thermometer at $90^{\circ}$ at sunrise, and the oppressiveness very great, and we were fully expecting more fatal results; but after mid-day the haze thickened, clouds formed, and came down in rain, thunder, \&c., giving us all new life. It became very hot again, but none of that oppressiveness, and continued so till about a week ago, when we again had rain, and since then the nights and mornings have been delightfully cool, and the day quite bearable under good cover ; the thermometer being only $86^{\circ}$." 


\section{LONDON SURGERY.}

In the Court of Queen's Bench, on Monday the 10th of December, a trial took place for damages, claimed on the ground of neglect and mismanagement in the treatment of a fractured thigh-bone, entailing upon the patient-a girl 11 years of age-shortening of the limb to the extent of two inches. Into the merits of this case it is not our intention to enter, farther than to express approbation of the verdict, which was against the plaintiff, who appears to have been one of those ungrateful, troublesome, and insolent individuals, always ready to become the tools of vindictive malevolence. But there were certain statements in the evidence that seem to require very serious consideration. Sir B. Brodie, Mr Guthrie, Mr Stanley, and Mr Bransby Cooper, were examined, and, as appears from the Times' report, deposed as follows :-

Mr Stanley. - "It was in the upper third of the thigh-bone. Such a fracture would be difficult of adjustment in an adult, but still more so in a child of that age, from the influence of certain muscles interfering with the bone, and producing a strain. I doubt whether, under the most favourable circumstances, the difficulty could have been surmounted."

Sir Benjamin Brodie.- "Upon the whole of the evidence, I see no reason to doubt that the child was properly treated. Such a fracture is very difficult to be treated ; and it is very seldom we can make the thigh as long as it was. It is generally attended with shortening of the limb."

Mr Bransby Cooper.- "I examined the child on Saturday. I think it was a good union, and not more deformity than I have seen in more favourable circumstances."

Mr Guthrie.- " The bone was irregularly united, but that could not be otherwise. He should say it was a good cure."-Times, December 11,1849.

[We hope that there are few surgeons, in or out of London, who would subscribe to these statements. Under peculiar circumstances, shortening of the limb, to some extent, may, and does, occur after fracture of the thigh-bone, without blame being fairly imputable to the practitioner. But, surely such a result should be regarded as the exception, and not the rule of practice. This we say, without any feeling of unkindness to the defendant, giving him full credit for the alleged difficulties of his case, and sympathising with the gentlemen, whose names have been mentioned, in their anxiety to rescue a young member of the profession, from what certainly looked very like the toils of an ill-natured conspiracy. But we must protest against any considerations being held to warrant statements so derogatory to the character of British surgery, and so much calculated to throw a shield of protection over carelessness and want of skill. How can it be expected that regular practice is to be upheld, and "bone-setting" put down, if the public are told, by the highest surgical authority of London, that fracture of the thigh-bone is seldom remedied without shortening of the limb-and that when this occurs to the extent of two inches, the recovery may be considered Good !]

\section{VARIETIES.}

Number of Students in Edinburgh.-The total number of students attending the University of Edinburgh, this year, is 1,274, being 90 more than last year. Of these, 412 attend the medical, 656 the literary, and 206 the law classes. The increase in the number of medical students, over that of last year, is 44 .

Quarantine in Cholera.-All Italy is covered with quarantines, in order to oppose the pretended contagion of cholera. Tuscany, Piedmont, Lombardy, and the two Sicilies, are defended by quarantines, which vary from two to ten days, according to the port from whence the vessel sailed. Sardinia and Elba have adopted similar measures, but the disease has already appeared in these 
islands, and it is not probable that sanitary cordons will accomplish there what they have failed to do in other places. There are some governments which seem incapable of deriving lessons from the past. -L' Union Médicale, Nov. 27, 1849.

School of Medicine at Constantinople.-This institution continues to flourish, and has lately been greatly improved by alterations introduced into it by Salich Effendi, first physician to the Sultan. A medical journal has also appeared-"The Medical Gazette of Constantinople," conducted by the director and sub-director of the Medical School.-Ibid.

M. Dumas and the Mineral Waters of France.-One of the first acts of M. Dumas, as Minister of Commerce and Agriculture, has been to invite the Committee of Public Hygiene to ascertain more exactly the utility of the mineral waters of France in the treatment of disease. For this purpose he has proposed to establish, at the different springs, clinical instruction for such students as have distinguished themselves in the hospitals, and requested the Committee to indicate to him,-1st, The establishments which, from their importance and the character of their springs, are most worthy of being studied ; and $2 \mathrm{~d}$, What number of students should be attached to each establishment, and what should be the duration and nature of their studies.-Gazette Médicale, Nov. 24, 1849.

Honours conferred on French Medical Practitioners for their Services DURING the Cholera.- All the French journals have lately given an account of honours, conferred by the President of the French Republic on those medical men who have been most active in their exertions during the cholera epidemic. The rank of Officer of the Legion of Honour has been conferred on Drs Melier and Rostan ; the cross of that order on Dr Stuart Cooper, and twelve other physicians ; and medals of honour on a great number of citizens of all ranks, professions, and countries.

Liberty of Medical Practice in the United States.-Virginia has, for a population of $1,239,797,1,517$ medical practitioners, or 1 for 812 individuals. In the Transactions of the American Medical Association, the following attempt is made to classify 972 of the above :-Licentiates of medical schools, 678 ; possessing no diploma, 249 ; student of two years, 1 ; of one year, 10 ; of shorter periods, 4. There remain 228 who have commenced practice some fine morning, without any previous preparatory study. And why not ? says Jonathan; so much the worse for those who consult them! If everybody is permitted to vote for the representatives of the country - to choose its president-why should anybody be prevented from choosing his own doctor? In choosing a bad representative, a man endangers the country and society at large, but in selecting a doctor, if he makes a mistake, it can only hurt himself.

Prize for the Preparation of Artificial Quinine.-The Societé de Pharmacie of Paris offers a prize of 4000 francs for the production of artificial quinine-i.e., of the alkaloid, formed without the use of cinchona, or other vegetable containing quinine. If quinine cannot be produced, the prize will be given to the person who exhibits a new vegetable principle, natural or artificial, resembling quinine in its properties, and capable of being used instead of it in medical practice. All memoirs on the subject to be addressed to the secretarygeneral of the Societé, before the 1st January 1851.

American View or Homgopathy.-The genteel Lilliputian quackery of our day, which bears the imposing name of homœopathy, is another example of the utter absurdity of rejecting all experience and common sense, for the sake of a baseless theory : a system which, as the sailors say of a ricketty ship, is only kept together by its paint. Homœeopathy is a thing of words, without ideas; a wild dream of medical indigestion, without coherence of parts, or basis of fact. It is unreality set to practice nothingness.-American Journal of Dental
Science. 